4. Einstein, A.(1954). Gluck : Sein Leben - seine Werke. Zbrich. Stuttgart : Pan-Verlag [in German].

5. Rice J. A. (1998), Antonio Salieri and viennese opera. Chicago : University of Chicago Press [in English].

Стаття надійшла до редакції 05.04.2017

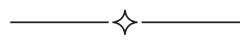

УДК 78.03.78

\author{
Ван Минизе \\ соискатель Одесской национальной музыкальной \\ академии имени А. В. Неждановой \\ odma_n@ukr.net

\section{ЛИРИЧЕСКИЙ ГЕНЕЗИС МУЗЫКИ И НАД-, ВНЕИНДИВИДУАЛЬНЫЕ ФОРМЫ ЕГО ПРОЯВЛЕНИЯ В ХРАМОВОМ ГИМНОПЕНИИ КИТАЯ И ЕВРОПЫ}

Цель работы. Исследование связано с поиском лирического принципа выражения по его генезису и развитию в культовом гимнопении. Недооценка религиозных истоков искусства в музыкальной сфере чревата потерей ориентиров на идеальную специфику этого вида творчества, что в условиях современной экспансии шоу-бизнеса затрудняет сохранность этого рода художественного достояния. Методология исследования определяется опорой на интонационное видение специфики музыки, ито вводит стилевой компаратив и историко-логический методы в качестве базовых, позволяя выявить смысловую парадигматику музыки, заложенную ее ритуально-религиозным истоком. Научная новизна состоит в расширении представлений о лирике как обусловливаемой вне- и надличностным характером выразительности храмового пения. Сравнительный анализ храмовой лирики в Китае и в Европе выводит на универсально-человеческие принципы музыкальной выразительности, черпающие в культе истоки высокой абстракции ее символики и экстатики. Выводы. В гимнопении происходит формирование лирической полноты возвышения над бытийностью - в пении как преодолении речевой ограниченности диапазона, как гипертрофии круговых движений голоса в виде фигуративных построений, как способ запечатления высокого без-волия, противостоящего моделям волевых устремлений, которые имеют место в музыке, выстроенной в гармонической вводнотонности.

Ключевые слова: лирический генезис, лирика, гимнопение, храмовость. 
Wang Mingjie, degree-seeking in Odessa National A. V. Nezhdanova Academy of Music

Lyrical genesis of the music and on-, outindividual forms of his manifestation in temple chant of China and Europe

Purpose of Work. The research is linked with the search of lyrical principle of expression under its genesis and development in cult hymn singing. Underestimation of religious origins in musical sphere fraughts with loss of orienteers to ideal specific features of this kind of creativity, that in the terms of current expansion of show-business makes difficult preservation of this kind of artistic legacy. Methodology of the research is defined by basing on intonational view of music specific featuresintroducing style comparative and historic-logical methods as basic ones enabling to find the sense paradigm of music provided by its ritual-religious origin. Scientific noveltylies in widening the understanding of lyrics as caused by beyond-and over-personality character of expression of temple singing. Comparative analysis of temple lyrics in China and in Europe leads to universal-human principles of musical expressiveness, taking in the cult the origins of high abstraction of its symbolism and ecstatics. Conclusions. Hymn singing includes formation of lyrical fullness of ascension over routine - in singing as overcoming speech limitation of range, as hypertrophy of circular movements of voice in figurative formations as a way of fixation of high absence of willfacing models of willful strivings having place in music built in harmonic tone-introduction.

Keywords: lyrical genesis, lyrics, hymn, temple

Ван Мінизе, здобувач Одеської національної музичної академії імені А. В. Нежданової

Лірична генеза музики та над-, позаіндивідуальні форми ї̈ виявлення у храмовому гімноспіві Китаю і Європи

Мета роботи. Дослідження пов'язане з пошуком ліричного принципу вираження за його генезою і розвитком в культовому гімноспіві. Недооцінка релігійних витоків мистецтва в музичній сфері загрожує втратою орієнтирів на ідеальну специфіку цього виду творчості, що в умовах сучасної експансії шоу-бизнесу утруднює збережкення цього роду художнього здобутку. Методологія дослідження визначається опорою на інтонаційне бачення специфіки музики, що вводить стильовий компаратив та історико-логічний методи у якості базових, дозволяючи вяивити значенневу парадигматику музики, закладену ї ритуально-релігійним витоком. $\mathbf{H a -}$ укова новизна полягає в розширенні уявлень про лірику як зумовлювану поза- та надособистісним характером виразності храмового співу. Порівняльний аналіз храмової лірики в Китаї та в Свропі виводить на універсально-людські принципи музичної виразності, що черпають у культі джерела високої абстракції їі символки і екстатики. Висновки. У гімноспіві спостерігається формування ліричної повноти піднесення над буттєвістю - у співі як подоланні мовленнєвої обмеженості діапазону, як гіпертрофії кругових рухів голосу у вигляді фігуративних побудов, як спосіб 
втілення високого без-волія, яке протистоїть моделям вольових устремлінь, що мають місие в музиці, вибудованій в гармонічній ввіднотоновості.

Ключові слова: ліричний генезис, лірика, гімноспів, храмовість.

Актуальность темы работы обусловлена современным состоянием музыкального искусства, устремленного, в итоге постмодернистского пласта конца XX - начала XXI века, к отодвижению культа драматизма-трагизма в искусстве в пользу созерцательния и лиризма выражения. Иллюстрацией является успех в масс-культурном ареале прошедших десятилетий старинной придворной лирической китайской оперы куньцюй, широкое распространение мифологенныхмистериальных срезов в оперном деле, чему замечательным свидетельством являются «Святой Франциск Ассизский» О. Мессиана и «Первый Император» Тань Дуня, ставшие знамением современных оперных исканий. Соответственно ритуально-религиозный дух, наполненный надличностным этосом лирического высказывания, определяет существо музыкальных наполнений театрализованных действ и зрелищных мероприятий современности, определяющих и специфику оперных постановок классики.

Целью данной работы является осмысление лирического принципа выражения по его генезису и развитию в культовом гимнопении. Конкретные задачи работы: 1) систематизация материалов по проявлению лирического в его ритуально-культовых основаниях; 2) прослеживание исторических путей становления жанровых и стилевых типологий, надличностной лирики религиозных песнопений Востока и Запада.

Методология исследования определяется опорой на интонационное видение специфики музыки, что вводит стилевой компаратив и историко-логический методы в качестве базовых, позволяя выявить смысловую парадигматику музыки, заложенную ее ритуально-религиозным истоком.

Научная новизна полученных в анаизе данных состоит в расширении представлений о лирике как обусловливаемой вне- и надличностным характером выразительности храмового пения. Сравнительный анализ храмовой лирики в Китае и в Европе выводит на универсально-человеческие принципы музыкальной выразительности, черпающие в культе истоки высокой абстракции ее символики и экстатики.

Изложение основного материала. Понятие «лирики» неоднократно осмыслялось в искусствоведении - с опорой на этимологическое значение данного слова-термина: «пение под лиру» (см. сведения из 
справочного энциклопедического издания: «...от греческого lyrikys, то что произносится под звуки лиры» $[15,713])$. Краткость описания-разъяснения названного феномена выражает некоторую емкость, выводящую на понятийное определение: речь идет о тонности инструментальной «поддержки строя» при декламации-пропевании стихов, то есть в особо приподнятом дыхании - как бы «бесконечного» по сравнению с расчлененным высказываниемм-фразировкой слов-значений в бытовой речи.

Оперное искусство зародилось и развивалось под знаком жанра музыкальной драмы, хотя первоначальное название «драма с музыкой» (drama per musica) точнее указывало на церковный генезис выразительности оперного пения, которое по своей жанровой основе составляет славильную лирическую сферу.

Отметим то, что специальные музыкальные справочные издания (включая замечательную 6-томную «Музыкальную энциклопедию», М., 1972-1982) «игнорируют» данное понятие в самостоятельности его значения, поскольку пояснения относительно словосочетаний «лирическая опера», «лирическая трагедия» и др. присутствуют [10, 279-280]. Данные положения поясняются традицией трактовки «лирического» качества относительно специфики искусства слова («... один из основных родов художественной литературы...» $[9,395])$. Причем, как видим, отмечается «род», то есть жанровый тип, точнее «метажанровый», который охватывает совокупность жанров, полнота типологических черт которых концентрируется в лирике, эпосе и драме: «...дин из основных родов художественной литературы (наряду с эпосом и драмой)» [9, 395].

Так в специальной литературе констатируется наличие трех основных принципов художественного мышления, которые рождают разные показатели его составляющих: драматического, эпического и лирического начал мышления-искусства. Два последние, особенно последнее (лиризм) неотрывны от музыкальных способов проявления. Что касается первого (драматизм), то, как известно, первичное значение этого слова является синонимом «трагедии», то есть мистериального действа с музыкальной составляющей, однако со временем, в постренессансной Европе «драматическим» осознается принципиально речевой и светский в своей основе театр или принцип проявления этого театрального качества.

Не забываем, что в основу драмы (и «драматургии», которая выросла из драматических основ театральных действ Европы Нового 
времени) положена диалектика диалога: с диалогизации тропа начинался театр как таковой, тогда как «тропирование» певческим хоровым гимнопением поддерживалось как монистичность-целостность литургической драмы. Последнюю Г. Кречмар справедливо считает началом-истоком оперы, поскольку в ней все пелось от начала до кониа представления [8, 21]. Тем самым акцентируется принцип оперыseria, которая родила собственно оперную практику bel canto, впрямую «продолжение» церковного театра. Диалогизация, вводившая антитезы, с позиций христианской целосности мировосприятия как Божественной благодати, отстраняет мир человеческих отношений и правящих в нем страстей.

Наиболее выраженным определением лиризма выступает короткая формула, приведенная в словаре В. Даля: «Лирическая поэзия противопоставляется эпической и включает в себя: оды, гимны, песни, где господствует «не действие, но чувство». И в качестве резюме: «Лиризм... возвышенное, вдохновенное песнопение...» [6, 254]. Как видим, лирика и мелодизм-вокал - синонимизируются.

Лиризм в целом связывают с «...выявлением эмоционального отношения автора или его героя к объекту изображения». Уточнение характеристики лирики осуществлено как достояния «общественно-политического», «философского» и «интимного» выражения [9, 395]. Такого рода формулировка констатирует, что из трех признаков лирики два («общественно-политический» и «философский» типы выражения) связаны с описанием коллективного субъекта - носителя «лирического» качества - и «чуткого, склонного к переживанию размышлений, чувств, переживаний» $[9,395]$. И только один признак («интимная» лирика) указывает на индивидуальный смысл выявлення лирического.

Указанное уточнение существенно, когда идет речь о лиризме как ментальном признаке, например, о показателе национального мышления украинцев, как это сделано в социологических очерках, собранных в книге с симптоматическим названием: «Українська душа» [17]. Так из понятия искусствоведения лиризм осознается в аспекте соииологической категории, когда идет речь об особого рода «чуткости», «склонности к переживанию» такого коллективного субъекта как нация.

При этом делается ударение на географической обусловленности черт национального характера: из «волнообразной мягкости» украинской лесостепи выводится - лиризм-эмоциональность населяющего эту лесостепь народа $[17,53]$. 
Другой из авторов вышеназванной книги противопоставляет «пластичность» греческого эпоса украинскому, который «погружает» реальный исторический мир в душевную материю, в лирическую песенность $[17,106]$. Тут лиризм уравнивается с мелодической фактурой, уживается с мелодической выразительностью пения. В другом месте названной книги, говоря о «пластике души», автор указывает на мягкость-изменчивость ее проявлений, характеризуемую как «волнообразность». Исследователи видят лиризм «украинской души» - в особого рода направленности семейных отношений у представителей этой нации на материнскую любовь $[17,70]$. Именно с культом материнства связывал Б. Цымбалистый «украинский кордоцентризм», то есть «украинскую философию сердца» [17, 87].

В принципе, данный подход соотносим с принципом жэнь - человеколюбие конфуцианства, в котором «ум сердца» как вместилища идеально-небесного начала определяет принятие в виде поведенчески-мыслительного принципа идей-чувств преданности, почтительности по отношению к старшим, великодушия и т. д. Особенно существенны позиции о соотношении ли и ци, которые которые обозначились в концепции Чжу Си в эпоху Сун (грань XI-XII вв.) и в которых ли как разумная творческа сила обусловливает нравственный позитив благородных людей [7, 217] (ср. со «сковородинским человеком» у вышецитированного Б. Цымбалистого и др.). В китайской философии именно конфуцианский принцип жээь поддерживал особую значимость мелодической лирики гимнов-од, которые составили смысл Книги Песен, Шицзин, до сего дня направляющих песенно-лирическое творчество великого Китая.

Учитывая сказанное, обращаемся к музыкальному проявлению «лиризма характера нации» - исключительной склонности к «песеннолирической» сфере, к мелодизму, поддержанному гетерофонно-подголосочной полифонией, которая образует существенную составляющую музыкально-культурной продукции любой нации и которая в культуреискусстве ряда европейских народов обрела эмблематический смысл. Таков ариозно-песенный комплекс, который неотторжим от представлений об итальянской нации и с которым исторически сопряжено национальное самоутверждение страны. Песенно-шансонное достояние, генетически полифонический, то есть духовно-высокий облик этого символического для Франции ее художественного проявления.

С лирикой спряжено в искусствоведении понятие романтизма как художественного направления, которое охватывает эпоху евро- 
пейского развития искусства и которое обращает внимание на достоинства лирики, лирической поэзии в особенности. Лиризм в его музыкальном воплощении составляет нечто противоположное драматическому и эпическому планам выражения, придавая целому монологичность, которая неотделима от выражения вдохновенного пения, надбытийный смысл которого выражается в объемности диапазона, охватывающего напряженные регистры высокого фальцетного пения и принципиального «басения».

В этом плане показателен лиризм китайской певческой традиции, в которой устойчиво тяготение к высокой тесситуре, к «звенящим» регистрам, соотносимым, по наблюдению У Голин [16, 6], с речевыми звучаниями восторженно-вежливого обращения. Эта связь лирического с мелодическим «парением в высях» европейские поэты осознавали в связи с художественным опытом Востока и Китая в особенности. В иллюстрацию ссылаемся на стихи великого русского поэта-лирика К. Бальмонта, для которого китайский Восток - это «пробел лирического зноя» и постигаемый «сквозь легкий нежный стих / Безбрежное отчаянье покоя» $[3,186]$.

Лиризм как полнота проявления пафоса восхищения, то есть воспевания, образно точно запечатлеваемого в жанровой типологии гимна, определила сакральные основания музыки вообще, исконное назначение которой дано возвышением над бытийностью и погружением в идеальные сущности Неба и Веры. Лиризм выстроен на воплощении высокой умиленной радости, которая стремится к экстатическому продлению своего воплощения, соответственно исключает волевую целеустремленность преодоления, реализуемую в мелодической волновой-круговой последовательности тоновых сопряжений. Отсюда, по Б. Асафьеву, не гармонические закономерности вводнотоновых тяготений гармонических ладов, но полнота тоновой сменности мелодической тоникальности решает судьбу лирических проявлений в музыке.

Лиризм, органично реализуемый в мелодическом пении (одноголосном, гетерофонно-многоголосном), ориентируется на интонационные показатели речи - см. явление «среднего тона» высказывания в различении типов речевых интонаций по Е. Брызгуновой [4]. Аналог этому находим в античной «мезе» как тоническом звуке в середине ладовой структуры, аналогично - опорность тона в середине знаменных мелодий в старофранцузской песенности с эффектами «субкварты» и т. п. Однако непосредственное моделирование речевых интонаций не составляет специальной цели храмовой культуры, тем 
более в храмах классически религиозной традиции типа буддистской, христианской, исламской. Именно в практике религиозного пения эпохи господства классических религий рождается вокальность как таковая: распевание внутри слоговых конструкций (см. понятие «вокализации» [5, 829]).

Параллельно с развитием лиризма как чистоты мелодических построений гимнопевческого искусства складывалось искусство мистерий, бывших достоянием тайнодейств Античности и обретших в европейском Средневековье, прежде всего в Византии, полноту символического проявления, ибо не жизнеиспытательные физические в том числе приношения языческих мистерий Озириса - Изиды, Таммуза, Орфических, Элевсинских, Самофракийских, Друистических и им подобных действ $[15,810]$, но театрализованно-художественно подаваемая священная история, в которой нарочито сочеталась вокальность молитвопения и бытовые комические эпизоды, начало которым составила поданная в Византии от VII в. традиция; в исследовании Т. Акиндиновой и А. Амашукели неоднозначно заявлено: «... театрализация богослужения на христианском Востоке имеет свои истоки. Мистерии были распространены в Византии...» $[1,75]$.

Литургийный смысл лирического гимнопения осознан был выделением в провизантийски ориентированной Франции XII века, где сложилась литургическая драма, отличие которой от мистерии определялось тем, что она пелась от начала до конца, внедряя самозначимость вокала в музыкальное оснащение богослужения.

Б. Асафьев, исследуя феномен мелодизма, выделяет «чистую мелодику... мыслимую вне гармонии», в которой действуют «два основных закона: 1. Закон смены тонов (внутри лада)... 2. Закон строгой экономии и отбора внутриладовых тонов: если взят скачок, он заполняется недостающими голосами... Отсюда и интонационная симметрия...» [2, 231]. И далее музыковед поясняет:

«Но оба эти закона действуют в условиях интонируемой - развернутой в движении, действии и самодовлеющей (а не гомофонной) мелодики...». И далее: «Очень интересно наблюдать закон заполнения 'прорывов' плавностью движения тонов в мелодико-пентатонном (курсив здесь и дальше наш. - B. М.) стиле. Этот стиль можно считать строгим стилем в эволюции мелодии, и эпохи его господства - эпохами строгого мелодического стиля. Прогресс этого стиля - в смысле обогащения его стилевой же гармонией (без вводных тонов) - вполне возможен» [2, 231]. 
Как видим из приведенного фрагмента, Асафьев откровенно прогнозировал тот поворот к «строгому мелодическому стилю», который наблюдаем в наши дни и персоницирован творчеством Тан Дуна и Юна Исанга как представителей культуры Дальнего Востока в европейской системе композиции, а пентатонность для них стала ладовой матрицей музыкально-мыслительных операций. Речь идет о «чистом» мелодизме, уходящем от сплавов с речевыми интонационными конструкциями, воспроизводящими волевые импульсы, прежде всего, индивидуального волеизъявления, на воплощение которого рассчитан эффект вводнотоновости в гармонических лада европейского мажоро-минора (об этом специально, о моделировании волевых усилий в гармонической ладовой функциональности, писал В. Медушевский в 1976 г. [14])

Мелодизм в чистоте проявления «интонационной симметрии» (см. выше у Асафьева) уходит от речево-экспрессивных «выбросов», представляя то небесное совершенство, которое ценил Конфуций и которое отличало в Европе сакрально-церковный пласт, сохраненный от раннехристианской традиции в русском и украинском, болгарском православии. Именно о мелодической симметрии круговых движений пишет В. Мартынов, выделяя специально храмовую музыку, отличную от принятой в миру и непосредственно воспроизводящую душевное движение обращенного к Богу верующего: «...Согласно святоотческому учению, молящаяся душа совершает именно кругообразное движение...» $[13,59]$. «Мелодика богослужебного пения предназначена... к внутренней сущности молитвы», «мелодический континуум есть круг мелодических структур... мелодический круг находит свое воплощение в принципе и осмогласия $[13,65] »$.

Ясно, что мелодическая симметрия в стремлении к бесполутоновости в случае старохристианских молитвопений не может апеллировать к индивидуальному чувству, но принципиально ориентирована на собирательность-«соборность» выражения. Но этот же смысл несет и пентатонность традиционной китайской гимнической лирики, бывшей для Конфуция воплощением «человечности в человеке», то есть того высокого-собирательного, которое имеется в индивиде и типологизирует в высоком же смысле его самовыражение. Этот же смысл на базе тетрахордности имела и лирика Пифагора, в которой декламация стихов на тонности идеально настроенной лиры вносила типово-музыкальной интерваликой сколок небесного-мусического в высказывание декламирующего-поющего субъекта выражения. 
В работе Лю Бинцяна находим остроумное наблюдение «пентатонного-ангемитонного просветления» лирики церковного пения в Европе IX-XI вв., особенно наглядно проступающего в случаях осознанного преобразования на христианский лад греческих античных гимнов: «Итак, в европейском средневековом мелодическом обиходе, составившем наследие Античности, выделяется диатоника с подчеркнутыми ангемитонными последовательностями... Достаточно сравнить Гвидо-гимн (Х в.) и Оду Горация... из которой явно «произросла» знаменитая мелодия, закрепившая названия ступеней гексахордной диатоники ut-re-mi-sol-la, чтобы продемонстрировать ангемитонное просветление античного источника. Последний, как известно, питался древнегреческой теорией тетрахордной, поступенно-заполненной, организации ладов, в которых положение полутонового хода создавало отличительно-разграничительный показатель. Привнесение ангемитонности в мелодику центрального Средневековья является наработанным христианской практикой качеством, что имеет свое специальное объяснение» [11, 99].

И далее цитируемый автор предлагает следующее объяснение ситуации «приближения к пентатонике» церковных христианских мелодий: «Неоспорима исключительная роль христианизированных кельтов, галлов и ирландцев, в распространении христианства на европейском Западе... В Европе средоточием ирландской - провизантийской - учености стал Санкт-Галленский монастырь, прославившийся благодаря творцам секвенций Ноткеру и Туотило, носителям кельтской христианской традиции, - при том что в фольклоре этих народов 'преобладают песни, построенные в пентатонных ладах'... В сопоставлении Секвенции Ноткера (IX в.) и раннехристианской версии Аллилуйа, содержащей преемственные черты по отношению к еврейской храмовой псалмодии... и явно послужившей основанием в выстраивании христианского гимна, - очевидно ангемитонное 'nрояснение' мелодии твориа Секвенции» [11, 99-100].

Данное разъяснение Лю Бинцяна тем более значимо, что в современной литературе настойчиво обсуждается проблема миграций прагаллов сначала с Севера Европы на Юг и в Азию, а затем в обратном направлении, в том числе это касается судьбы народа тохаров-юэжчи, бывшего в непосредственной близости к Китаю и отмечаемого галльско-индоевропейскими анатомическими и культурными признаками. Их государство было разгромлено, но вероятность возвращения в Европу уцелевших представителей праевропейского этноса поддержана 
множественными топонимами от Забайкалья и Каспия до крайнего Запада Европы. Так что, возможно, предки ирландцев-шотландцев и галлов-французов сознательно привнесли опыт пользования «чистым мелодизмом» на пентатонной основе, который со времен Конфуция в Китае образует парадигматический пласт культуры пения.

Выводы. Приведенные исторические данные свидетельствуют об универсальном смысле лирических - гимнических-надиндивидуальных - начал музыки, о сосредоточении музыкальной энергетики в сфере культа, в религиозных акциях и в ритуально-мифологизированных действах.

Итак, лирический генезис музыки создает следующие условия продвижения лирики в ритуалике-культе и в раннем театре:

1) лирический смысл явлений обозначается сопричастностью тоново-ритмически упорядоченного звукоизвлечения в лирике к запечатлению надбытовых реалий идеальных человеческих влечений;

2) лирическая выразительность базируется на мелодической вещественности, отражающей круговые-волнообразные симметричные структуры космических совершенных пропорций, которые противостоят единично-человеческим речевым проявлениям и, одновременно, регулируют посредством ориентировки на «средний тон» речевые интонационные колебания (отсюда - универсальность интонационного принципа в музыке как соотнесения вербального и музыкального звуковыражения);

3) формирование лирической полноты возвышения над бытийностью - в пении как преодолении речевой ограниченности диапазона за счет фальшь-регистров (высокого и низкого), как гипертрофии круговых движений голоса в виде фигуративных построений, как способ запечатления высокого без-волия, противостоящего моделям волевых устремлений, которые имеют место в музыке, выстроенной в гармонической вводнотоновости.

\section{СПИСОК ЛИТЕРАТУРЫ}

1. Акиндинова Т., Амашукели А. Танец в традиции христианской культуры. 2-е изд., испр.и доп. СПб.: Издательство РХГА, 2015. 239 с.

2. Асафьев Б. Музыкальная форма как процесс. Москва; Ленинград: Музыка, 1971. 379 с.

3. Бальмонт К. Избранное. М.: Правда, 1990. 608 с.

4. Брызгунова Е. Звуки и интонации русской речи. Лингафонный курс для иностранцев. М.: Прогресс, 1972. 251 с. 
5. Вокализация. Музыкальная энциклопедия: в 6 т. / гл. ред. Ю. Келдыш. М.: Советская энциклопедия, 1973. Том І. А-Гонг. С. 829.

6. Даль В. Толковый словарь живого великорусского языка. Т. 4. Москва: Русский язык, 1980. 683 с.

7. История философии: в 4 т. Москва: Издат. Академии наук СССР, 1957. T. $1.720 \mathrm{c}$.

8. Кречмар Г. История оперы. Ленинград: Academia, 1925. 406 с.

9. Лірика. Словник іншомовних слів. Київ, 1977. С. 395.

10. Лирическая опера. Лирическая трагедия. Музыкальная энциклопедия: в 6 томах. Т. 3. М., 1976. С. 279-280.

11. Лю Бинцян. Музыкально-исторические параллели развития искусства Китая и Европы. Одесса: Астропринт, 2014. 440 с.

12. Ма Вей. Концепция формы в музыке Китая и Европы: аспекты композиции и исполнительства: дис. ... канд. исскуств. 17.00.03. Одесса, 2004. 172 с.

13. Мартынов В. Культура, иконосфера и Богослужебное пение Московской Руси. М.: Прогресс-Традиция, Русский путь, 2000. 224 с.

14. Медушевский В. О закономерностях и средствах художественного воздействия музыки. М.: Музыка, 1976. 255 с.

15. Советский энциклопедический словарь. Москва: Сов. энциклопедия, 1984. $1599 \mathrm{c}$.

16. У Голін. Китайська виконавська інтонація в європейській вокальній музиці XIX-XX століть: автореф. дис. ... канд. мистецтв. 17.00.03. Одеса, 2006. $16 \mathrm{c}$.

17. Українська душа: збірник статей / вступ. стаття та ред. В. Храмової. Київ: Фенікс, 1992. 127 с.

\section{REFERENCES}

1. Akindinova, T. \&, Amakusheli, A. (2015). Dance in Christian Culture Traditions. 2nd edition, corrected and supplemented. Saint-Petersburg: Public House RCHA [in Russian].

2. Afanasev, B.(1971). Musical Form as Process. Moscow-Leningrad: Music [in Russian].

3. Balmont, K. (1990). Favourites. M.: Pravda [in Russian].

4. Bryshunova, E. (1972). Sounds and Intonations of Russian Speech. Lingual-Phonetical Course for Foreigners. Moscow: Progress [in Russian].

5. Vocalization. Musical Encyclopedia in 6 volumes. (1973) Moscow: Publisher Soviet Encyclopedia, Vol. 1 p.829 [in Russian].

6. Dahl, V. (1980). Explanatory Dictionary of the Living Great Russian Language: Vol. 4. Moscow: Russian Language [in Russian].

7. History of Philosophy in 4 volumes (1957). Vol.1. Moscow: Publishing Department of the Academy of Sciences of USSR, 1957. [in Russian].

8. Krechmar, H. (1925). History of Opera. Leningrad: Academia [in Russian].

9.Lyrics. Foreign Words Vocabulary (1977). Kyiv. p. 395 [in Ukrainian]. 
10. Lyric Opera. Lyric Tragedy // Musical Encyclopedia in 6 Volumes (1976). Vol. 3. p 279-280 [in Russian].

11.Liu Bingqiang (2014). Musical and Historical Parallels of Development of Art in Chine and Europe. Monography on History of Culture for Musical Academies, Universities and Art Higher Educational Institutions. Odessa: Astroprint [in Russian].

12. Ma Wei (2014). Concept of Form in Music of China and Europe: Aspects of Composition and Performance. Candidate's thesis. Odessa [in Russian]..

13. Martynov, V. (2000). Culture, Iconic Surrounding and Divine Singing of Moscow Rus. Moscow: Progress - Traditsiia, Russkyi Put [in Russian].

14. Medushevskiy, V. (1976). About Regularities and Means of Artistic Influence of Music. Music [in Russian].

15. Soviet Encyclopedic Vocabulary (1984) Moscow: Soviet Encyclopedia. [in Russian].

16. U. Holin (2006). Chinese Performance Intonation in European Vocal Music of XIX-XX Centuries. Extended abstract of candidate's thesis Odessa [in Ukrainian].

17. Ukrainian Soul (1992). Collection of Articles. Introductory Articles by V. Khramova. Kyiv: Feniks [in Ukrainian].

Стаття надійшла до редакції 12.04.2017

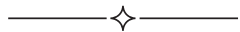

